\title{
NEURAL NETWORK AND TRAINING STRATEGY DESIGN FOR TRAIN DRIVERS' VIBRATION DOSE SIMULATION
}

\author{
Munoz-Guijosa, J. M.; Riesco, E. \& Olmedo, M. \\ Escuela Técnica Superior de Ingenieros Industriales, Universidad Politécnica de Madrid, \\ c/ José Gutiérrez Abascal, 2, 28006 - Madrid, Spain \\ E-Mail: JMGuijosa@etsii.upm.es
}

\begin{abstract}
Vibration can cause professional illnesses in train drivers, giving also rise to lawsuits to the employer. A possible cause may be the lack of systematic vibration estimation processes, due to operational complexities, subjectivities involved and the cost of dedicated tests. Estimation quality may be improved by using a driver seat model along with cabin floor vibration data acquired during the train dynamic approval tests. However, due to the nonlinearities present, analytical models frequently show inaccurate results. This work deals with the design of an appropriate neural network for predicting the seat-driver interface vibration, based on selected and processed cabin floor acceleration data obtained during the dynamic approval tests. Network type, input signals set and signal conditioning have considerable impact on the simulation accuracy. Results show good correlation between simulated and experimental data, even better between simulated and measured standard vibration dose indicators, being RMS errors between $3.9 \%$ and $9.4 \%$ and peak factor errors between $0.8 \%$ and $9.6 \%$.

(Received in May 2016, accepted in September 2016. This paper was with the authors 1 month for 1 revision.)
\end{abstract}

Key Words: Vibration Dose, Artificial Neural Network, Nonlinear Model, Train Engineer, Train Driver

\section{INTRODUCTION}

Given its harmful health effects, vibrations in the workplace become an increasingly more relevant issue. In Europe, directives have been issued since long time (e.g. [1]), aiming to establish a methodology for its assessment and control. Although regulations for proper vibratory design of the workplace exist [2-4], there is evidence that vibration may have caused illnesses, especially back pain and sciatica in drivers $[5,6]$ particularly in those driving old or poorly maintained material, with poor or wrong sized seats and circulating in low quality tracks. In the United States, lawsuits by employees subjected to excessive vibration [7-9], have meant payment of considerable sums by employers.

The measurement of vibrations received by the driver is simple. The standards are based on dose indicators which take into account the average square values of the vertical, transverse and longitudinal accelerations or its quadratic sum, measured on the driver-seat interface by means of an instrumented pad equipped with a triaxial accelerometer. The indicators take into account peak factors for overweighting acceleration peaks.

The ISO 2631-1 standard suggests the indicator $A(8)$ defined in Eq. (1) as the $R M S$ value of the weighted acceleration $a_{w}(t)$ measured during the $T=8$ shift hours, or the $V D V n$ (Vibration Dose Value) as defined in Eq. (2), as the quadratic root of the sum of the fourth power of the accelerations measured, used when shocks are present in the measured vibration, assessed in terms of crest factors. If $n=8, V D V_{8}=A(8)$ :

$$
\begin{gathered}
a_{w}=\left[\frac{1}{T} \int_{0}^{T} a_{w}^{2}(t) d t\right]^{\frac{1}{2}} \quad A(8)=\sqrt{\frac{1}{8} \sum_{n=1}^{n=N} a_{w n}^{2} t_{n}} \\
V D V=\left\{\int_{0}^{t}\left[a_{w}(t)\right]^{4} d t\right\}^{\frac{1}{4}} \quad V D V_{n}=\sqrt[4]{\frac{t_{n}}{t_{n \text { measured }}} V D V_{n \text { measured }}^{4}}
\end{gathered}
$$


However, the cost of a driver vibration measurement is high, involving the commissioning of a complete train and several commercial track sections for a substantially long time, and the use of a significant amount of human resources. For this reason, almost all the workplace vibration measurements are performed simultaneously with the vehicle dynamic approval tests. This makes drawing conclusions difficult. Firstly, due to the tight dynamic approval test planning, it is usually difficult to select, from the huge amount of track sections, those in which the seat vibration measurements are to be performed, so high variability in the results is to be expected. This fact also eases the possibility of biased track sections selection in order to get whether positive or negative results. Furthermore, it is difficult to instruct the driver in the measurement process, having to remain motionless for long periods, for preventing the contamination of the measures with movements on the seat.

However, many runs are carried out in the dynamic approval tests, in different track types, being many acceleration signals at different points in the cabin floor acquired and processed. Furthermore, such tests have been conducted since long, so extensive databases exist in both train manufacturers and operators. It seems reasonable to use such cabin floor vibration data to estimate the vibration dose received by the train driver. The manipulability factors described could be eliminated at a low cost by selecting offline data with enough quality and representative track sections from the extensive information available. A model describing the driver's seat dynamic behaviour is then necessary for inferring the seat-driver interface vibration as a function of the cabin floor accelerations. This approach has been proposed by some researchers [10-14], being the results useful for the design process. Nevertheless, the reported mathematical models show limited correlation with the actual vibration measurements. The main reason for the deviation is the nonlinear behaviour of the seat, due to the geometry of the seat suspension, the existing friction, the gaps existing between fixed and moving parts, and some types of dampers used in the seat suspension.

Artificial neural networks are used for modelling systems where complexity prevents a successful use of analytical approaches (for instance, $[15,16])$. Due to its constitution and fundaments, artificial neural networks (or simply ANN) have a number of characteristics similar to those of the human brain, as learning from experience, generalizing from cases already learned and applying the acquired knowledge to new cases, or extracting essential features from inputs including irrelevant information. This conceptual framework let us think that ANN can also be used in applications as the one this work deals with. Thus, this paper explores the possibility of using ANN for the prediction of the vibration received in the driver's seat. Few works have been found regarding the use of ANN for this application [1723] so we believe that the methodology presented and the results obtained in this work can be useful for the assessment of the vibrational environment at driver's place.

\section{ARTIFICIAL NEURAL NETWORKS. THEORETICAL BASE}

ANN are organized in layers (input, output, and hidden) made up of a number of neurons depending on the amount of data to be obtained (Fig. 1 a). Each neuron (Fig. $1 \mathrm{~b}$ ) is a mathematical entity composed of inputs, synaptic weights which amplify or attenuate such inputs, a sum operator or input product, an offset and a transfer function resulting in an output signal. In the network training phase, the real system input and output signals are available. The output signals provided by the neural network when excited with the input signals are compared to the real system output signals for the same inputs, and the average quadratic error is calculated. Synaptic weights and offsets are then modified and the procedure is repeated until the error lies below a tolerance value. The techniques based on neural networks use different algorithms for obtaining the desired model depending on the available data. In this work, the Backpropagation algorithm is used for determining the synaptic weights. It is a 
classical method of neural network training for the case of supervised learning - that is, real system outputs are available for network training. Once a pattern has been applied to the network inputs as a stimulus, it spreads from the first layer through the upper layers of the network to generate the outputs. The network outputs signals are compared to the real system outputs and an error signal for each of the outputs is calculated. The errors spread backwards from the outputs layer to all neurons in the hidden layer that contribute directly to each output. However, the hidden layer neurons receive only a fraction of the total error signal based on the relative contribution that each neuron has provided to the original output. This process is repeated layer by layer, until all neurons in the network have received an error signal describing their relative contributions to the total error.

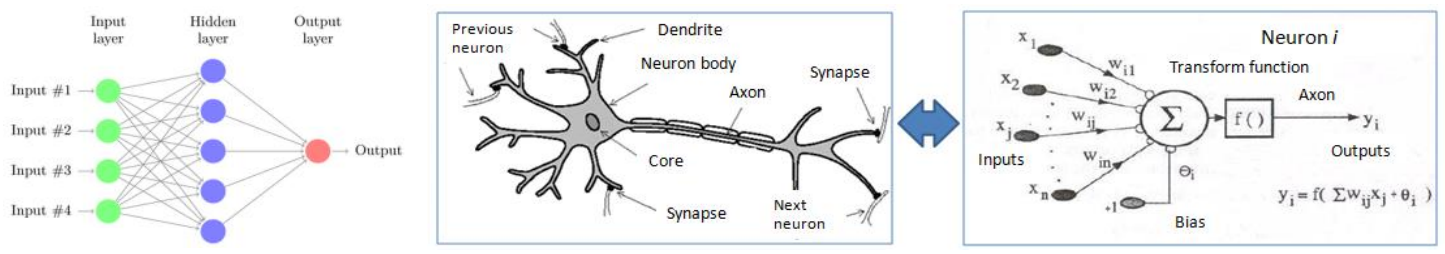

Figure 1: a) Neural network, b) Schematic representation of one of the network neurons.

The importance of this process is that, as the network is trained, the neurons in the intermediate layers organize themselves so that the different neurons learn to recognize different features of the total input space. After training, when an arbitrary input pattern that is incomplete or contains noise is presented to the network, the neurons in the hidden layer of the network will respond with an active output if the new entry contains a pattern that resembles a characteristic that the individual neurons have learned to recognize during the training phase.

\section{SYSTEM STUDIED}

The vehicle used in this work is a high-speed train that can also run on conventional tracks. The driver seat (Fig. 2) is scissor-type, equipped with back headrests, armrests, and suspension springs and dampers. Table I shows the seat's technical characteristics.
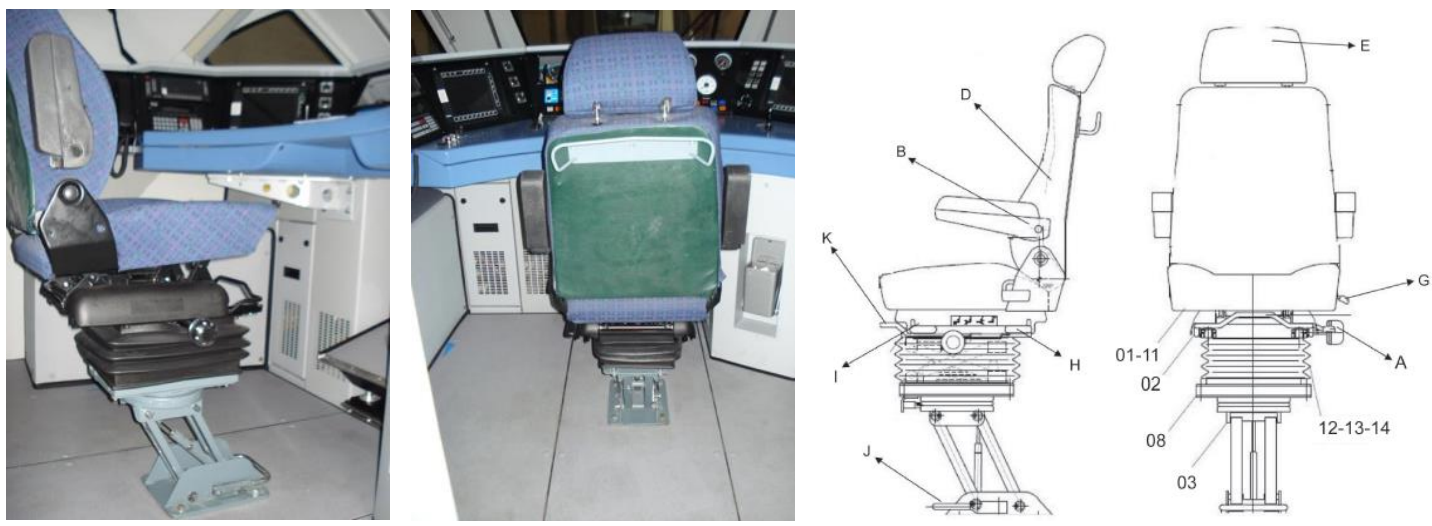

Figure 2: Seat used in the study; A - Vertical adjustment, B - armrest, C - suspension, D- Adjustable inclination backrest, E - Headrest, F - Joint, G - Inclination adjustment, H - Suspension buffer, I - Pad base, $\mathrm{J}$ - Base, $\mathrm{K}$ - Longitudinal adjustment.

The use of a spring-damper suspension guided through linkages, including linear guides with its corresponding friction - and mechanical stops, as well as the existing assembly clearances (both in the seat-floor attachment, the seat assembly elements and the springdamper) make the system highly nonlinear. 
Table I: Seat characteristics.

\begin{tabular}{|l|c|}
\hline Total width & $560 \mathrm{~mm}$ \\
\hline Total height & $1042-1187 \mathrm{~mm}$ \\
\hline Total depth & $555 \pm 220 \mathrm{~mm}$ \\
\hline Seat height & $665-725 \mathrm{~mm}$ \\
\hline Back inclination & $12^{\circ} / 27^{\circ}$ \\
\hline Seat inclination & $-4^{\circ} / 2^{\circ}$ \\
\hline Space between arms & $456 \mathrm{~mm}$ \\
\hline Armrest & $190 \mathrm{~mm}$ \\
\hline Seats depth & $440 \mathrm{~mm}$ \\
\hline Headrest height & $150 \mathrm{~mm}$ \\
\hline
\end{tabular}

Obviously, as the aim of this study is the determination of the seat-driver interface vibration with the dynamic approval test data, the instrumentation used for the evaluation of the neural network input data (Fig. 3 a) is the same than the one used during the dynamic approval tests. KISTLER 8304B2 accelerometers were used to measure the vehicle, bogie and cabin floor lateral and longitudinal accelerations. A Columbia Gyro SI 701 BHP was used to measure the $\mathrm{Z}$ axis angular speed. The vehicle speed signal was obtained from the anti-skid device sensor. A sampling rate of $250 \mathrm{~Hz}$ was used. A low-pass filter tuned to maximum one half of the sampling frequency was used for all the signals before the digital acquisition. A high-pass filter tuned at $0.4 \mathrm{~Hz}$ was used to eliminate the accelerometer signals related to track orography. All measured signals were digitally recorded in a hard disk system. Before the measurements, the deviations of the sensors' signals with respect to their calibration values were checked using the appropriate calibrators.

In addition to the devices used for dynamic approval test, and in order to validate the neural network, acceleration measurements were taken at the seat-driver interface using a PCB Piezotronics 356B41 seat pad equipped with a triaxial accelerometer (Fig. 3 b).

The cabin floor and seat vibration signals were acquired at several runs made at different track sections during the train dynamic certification tests, so that the dynamic behaviour in different situations (speeds, track conditions, curve radii, etc.) can be registered. This way, the neural network training is more extensive and a more general model can be obtained. Table II shows the characteristics of the sections of which data was used. Track types are classified according to the railway standard EN 14363.
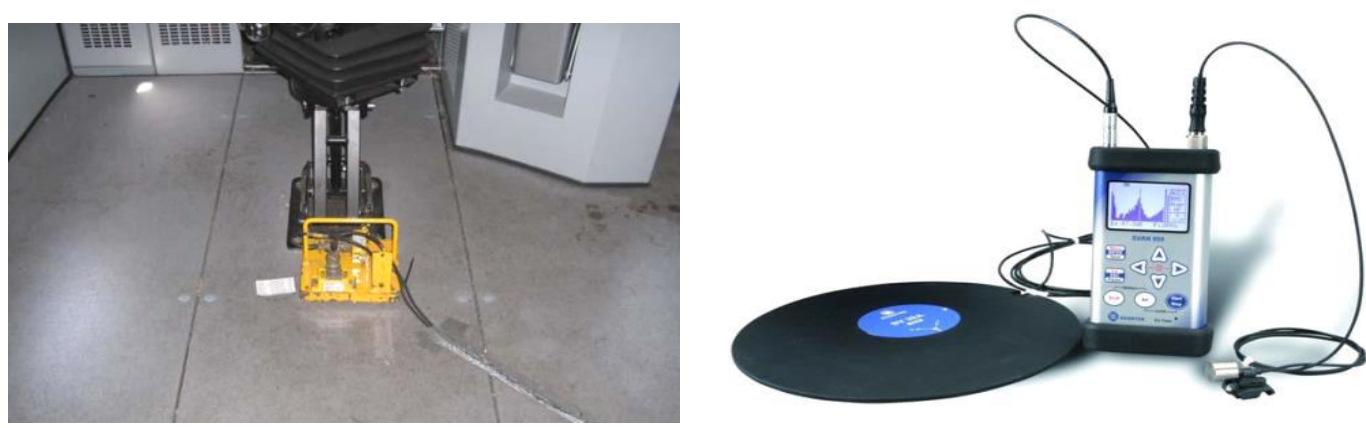

Figure 3: a) Instrumentation for the cabin floor vibration measurement, b) Instrumented pad for measuring the driver-seat interface vibration.

Fig. 4 shows the vehicle linear and Z-angular speeds in a QN2 type section with several curves. Fig. 5 shows the 5 seconds moving average cabin floor accelerations. In this case, corresponding to a section where the curves curvature radii are small, the lateral acceleration values are greater than those of the vertical acceleration. Fig. 6 shows a typical seat-driver interface acceleration measurement. 
Table II: Track sections used for dynamic data acquisition.

\begin{tabular}{|l|c|c|c|c|c|}
\hline \multicolumn{1}{|c|}{ Track type } & $\begin{array}{c}\text { Average } \\
\text { speed }(\mathrm{km} / \mathrm{h})\end{array}$ & $\begin{array}{c}\text { Radius } \\
(\mathrm{m})\end{array}$ & $\begin{array}{c}\text { Track } \\
\text { quality }\end{array}$ & $\begin{array}{c}\text { Section } \\
\text { length }(\mathrm{km})\end{array}$ & $\begin{array}{c}\text { Number } \\
\text { of runs }\end{array}$ \\
\hline $\begin{array}{l}\text { Curves of small radius } \\
\text { and low speed }\end{array}$ & 100 & $250<R<400$ & QN2- QN3 & $20-40$ & 3 \\
\hline $\begin{array}{l}\text { Curves of medium radius } \\
\text { and medium speed }\end{array}$ & 160 & $400<R<600$ & QN2 & 50 & 5 \\
\hline $\begin{array}{l}\text { Curves of high speed and } \\
\text { big radius }\end{array}$ & 200 & $600<R<5000$ & QN1- QN2 & 50 & 2 \\
\hline High speed curves & 250 & $5000<R$ & QN1 & 60 & 1 \\
\hline
\end{tabular}
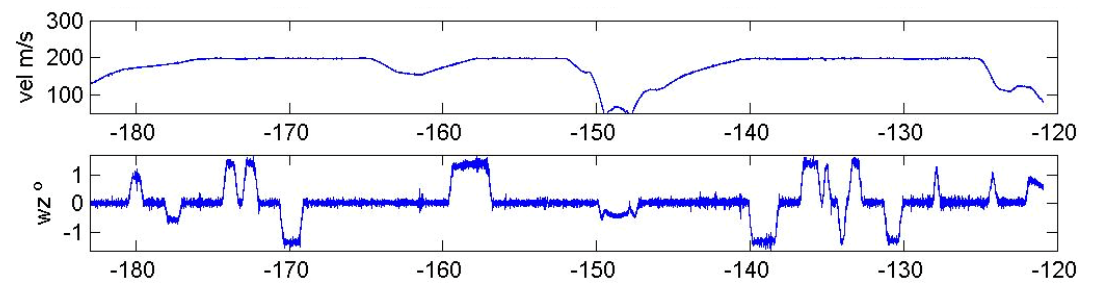

Figure 4: Vehicle linear and angular speeds recorded in a QN2 type track section; horizontal axis represents time in seconds.

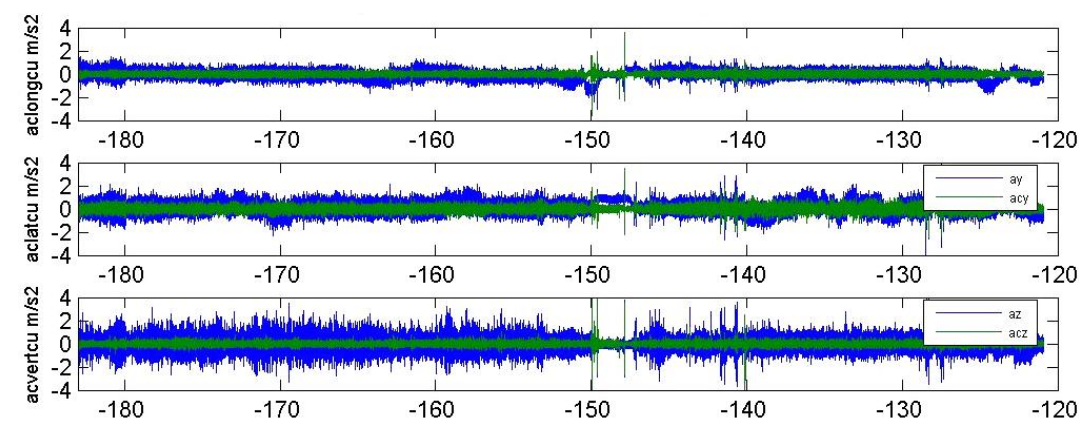

Figure 5: Cabin floor accelerations in a QN2 type track section; top: longitudinal acceleration, middle: lateral acceleration, bottom: vertical acceleration; note the similarity between the three superimposed lines at each graph (ISO, UIC); horizontal axis represents time in seconds.

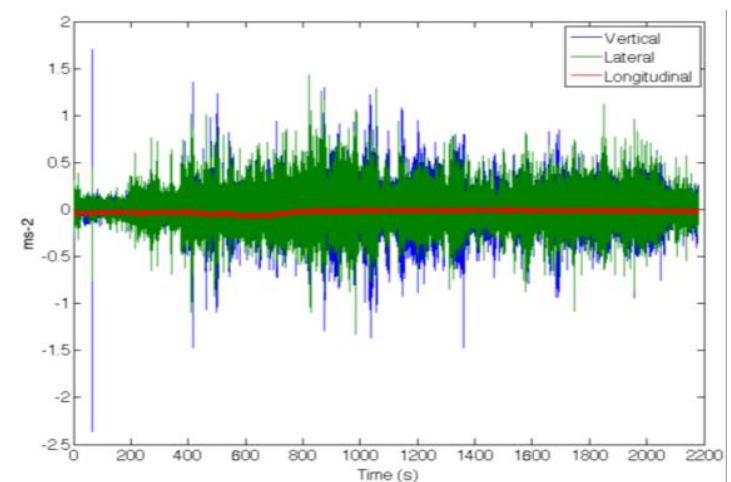

Figure 6: Seat-driver interface accelerations measured in a QN2 type track section.

\section{ARTIFICIAL NEURAL NETWORK DESIGN AND TRAINING}

In order to achieve the maximum correlation possible between the actual measured seat-driver interface accelerations and those generated by the ANN for the same cabin floor vibration input, certain stages must be carried out for the neural network design. A pre-processing of the input signals acquired in the vehicle dynamic certification runs is necessary, involving the sequencing of the registered data to isolate particular tracks with constant characteristics, 
finding representative data segments, and filtering such segments to the frequency range of interest, where vibration physiological effects are bigger (between 0,2 and $20 \mathrm{~Hz}$ according to ISO 2631-1). Furthermore, plausibility between the different input variables must be checked for removing, for instance, registers associated with driver sudden movements. In addition, a selection of the ANN input variables must be performed based on the search of input signals sets whose correlation to the output variables is relevant and allows for the biggest correlation possible between the ANN and real system outputs for the same input. After this processes, a set of data input segments with sufficient quality will be available to proceed to partial networks training (one per data segment). The final ANN, so-called "complete", will be set from the information resulting from the attachment of all the segments corresponding to sections with better results in the correlation of the partial ANN. Finally, the validation of the complete ANN will be performed, with sections that have not been used for the training.

\subsection{Neural network type and size selection, signal selection and pre-processing}

A neural network with one hidden layer will be used, with a sigmoid transfer function and a variable number of neurons, and an output layer with a linear transfer function and as many neurons as desired outputs. Both layers have feed-forward connections. This transfer functions combination was chosen because its ability of reproducing nonlinear signals. A resilient backpropagation algorithm was used for the network training.

Obviously, the ANN output variables must be those required for the evaluation of the driver vibration dose, which are vertical and lateral accelerations. It was decided not to include the seat-driver interface longitudinal acceleration as output variable, as it is found to be almost two orders of magnitude smaller than the other accelerations (Fig. 6) and leads to worse correlations in any neural network evaluated.

A selection criterion for the input variables is a graphical comparison of the registered values of the candidate input variables against the seat-driver interface lateral and vertical accelerations, in order to find some kind of relationship. Moreover, the cross-correlation matrix between the variables is obtained, looking for peaks in the expected dynamic response area ( 5 to $20 \mathrm{~Hz}, 0.2$ to 0.05 seconds) that allows for the detection of dynamic relationships between variables which may not be detectable through a graphical analysis. Fig. 7 shows both representations. Train speed and vertical and transverse accelerations are found to have a substantial correlation with the driver-seat interface accelerations.

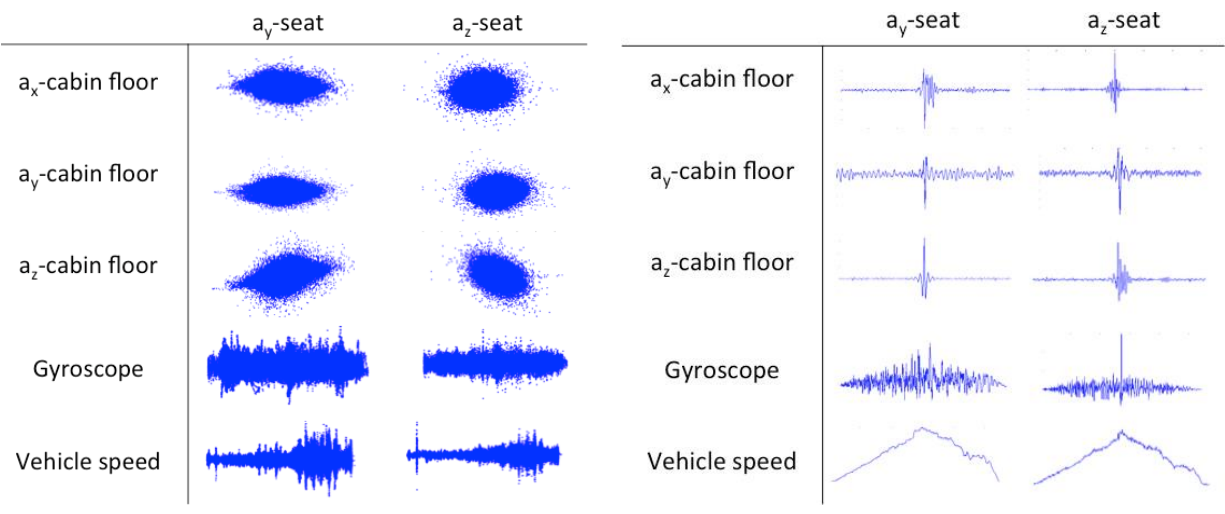

Figure 7: Study of relationships between input and output signals; left: graphical analysis, right: crosscorrelation matrix.

The data recorded in each channel for each of the different runs shown in Table II was divided in 50 data segments, in which vehicle speed is constant as depicted in Fig. 8, in order to later combine them and study the influence of the different vehicle speeds in the network training. After this division, signals in each data segment are filtered with a band pass filter 
between 0.5 and $20 \mathrm{~Hz}$. This frequency range encompasses more than $95 \%$ of the vibration energy content and is responsible for physiological effects, also eliminating the track orography.

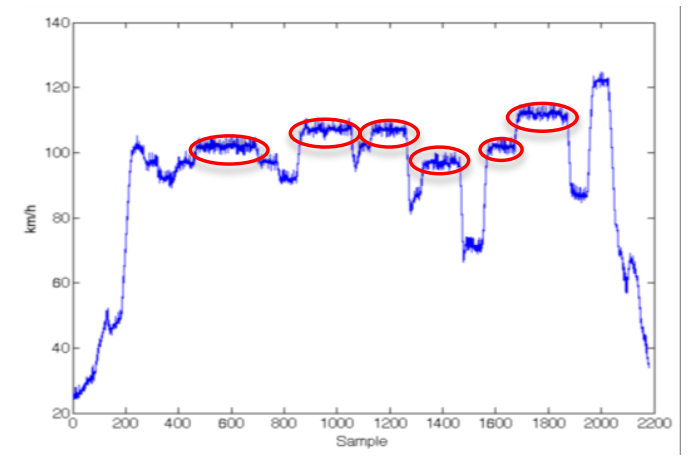

Figure 8: Division in data segments.

The plausibility of the collected data must be checked to eliminate sections with erroneous measures, which would introduce errors in the network training (Fig. 9). Segments where large sudden lateral accelerations with very low gyro values, indicating straight run, and segments where abrupt seat-driver interface vertical accelerations, not corresponding to floor vertical acceleration peaks, indicating driver movements, are removed.
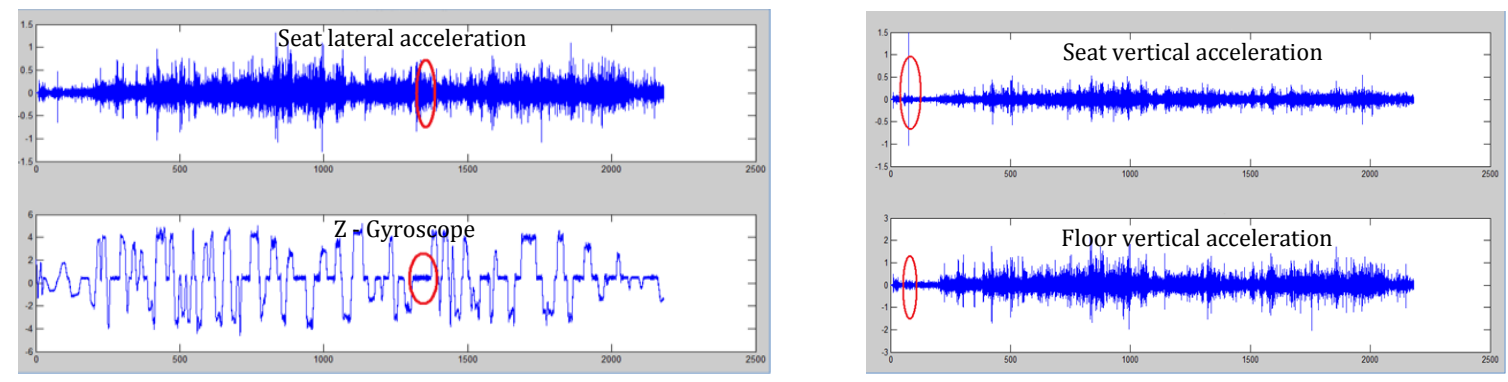

Figure 9: Plausibility of lateral acceleration (left) and vertical (right); horizontal axis represents time in seconds.

The number of neurons in the ANN hidden layer is determined so that a trade-off between accuracy and processing time is achieved, as shown in Fig. 10. From certain number of neurons on and the same sample length, an increase in the number of neurons does not lead to significant improvements in the ANN - real system output correlation, being however increased the processing time and the risk of generalization ability caused by overtraining. The use of the computer system resources is also to be considered, since large sample sizes may exceed the memory capacity. An optimal number of 75 neurons was selected.

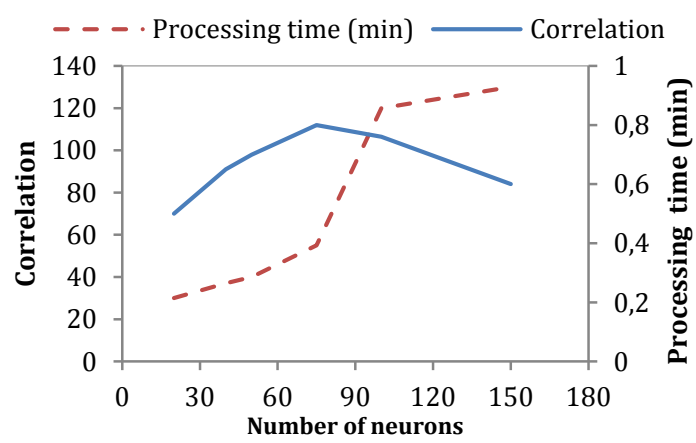

Figure 10: Influence of the number of neurons in the neural network - real system output signals correlation and processing time. 


\subsection{Network training and validation}

The influence of the pre-processing stage in the quality of each network is described in Table III. It is important to mention how the inclusion of cabin floor velocities, numerically integrated from the cabin floor accelerations, leads to a considerable increase in the correlation. Table III also shows how the acceleration filtering increases the correlation.

Table III: Effect of different strategies of pre-processing the input signals in the correlation obtained in the partial networks.

\begin{tabular}{|l|l|c|}
\hline \multicolumn{1}{|c|}{ Neural network input variables } & \multicolumn{1}{|c|}{ Neural network output variables } & $\begin{array}{c}\text { Worse output- } \\
\text { target correlation }\end{array}$ \\
\hline Floor non-filtered $\mathrm{x}, \mathrm{y}, \mathrm{z}$, accelerations & $\begin{array}{l}\text { Seat-driver interface non-filtered y, z } \\
\text { accelerations }\end{array}$ & 0,092 \\
\hline Floor filtered x, y, z accelerations & $\begin{array}{l}\text { Seat-driver interface non-filtered y, z } \\
\text { accelerations }\end{array}$ & 0,3 \\
\hline $\begin{array}{l}\text { Floor filtered x, y, z accelerations + floor } \\
\text { velocities }\end{array}$ & $\begin{array}{l}\text { Seat-driver interface non-filtered y, z } \\
\text { accelerations }\end{array}$ & 0,6 \\
\hline Floor filtered x, y, z accelerations & $\begin{array}{l}\text { Seat-driver interface filtered y, z } \\
\text { accelerations }\end{array}$ & 0,72 \\
\hline $\begin{array}{l}\text { Floor filtered } \mathrm{x}, \mathrm{y}, \mathrm{z} \text { accelerations + floor } \\
\text { velocities }\end{array}$ & $\begin{array}{l}\text { Seat-driver interface filtered y, z } \\
\text { accelerations }\end{array}$ & 0,85 \\
\hline
\end{tabular}

Finally, the inclusion of the driver's weight as an input signal was analysed. Obviously, the driver weight, in the same order of magnitude than the seat weight, has a crucial influence on the seat dynamic behaviour. On the other hand, driver's weight may not be available in the dynamic approval tests. However, it was observed that the inclusion of the driver's weight as an input in the ANN had a positive influence on the vertical acceleration correlations, but a neutral or negative influence on the lateral acceleration ones. This is caused by the much bigger seat lateral stiffness in comparison to the vertical stiffness. Consequently, it was decided to use two ANN with different output variables (transverse or vertical seat-driver interface acceleration); and also different input variables: cabin floor velocities and accelerations and gyroscope signal as input for the ANN which models the seat-driver interface lateral acceleration, and cabin floor velocities and accelerations and driver's weight as input for the ANN which models the seat-driver interface vertical acceleration (Fig. 11).

Once the ANN architecture is designed and the input data pre-processed, partial ANN were trained, each one with the data corresponding to each of the data segments. The data segments for which the partial ANN presented the best correlation levels were selected and stacked, creating a long data segment. Definitive complete ANN were then trained with this data. $70 \%$ of the data, randomly selected from the whole pre-processed dataset, was used for the network training. Fig. 12 shows the correlation results obtained in the training of the complete ANN for the seat-driver interface lateral and vertical accelerations, respectively. Lower correlation levels were obtained when simulating the vertical acceleration, due to the influence of the weight of different drivers on the readings of the accelerometers placed on the pad, which also indicates that this factor does not greatly influence the lateral acceleration, so the hypothesis about not entering the weight in the ANN that simulates the lateral acceleration is correct. However, driver's weight seems to have a bigger effect on the vertical acceleration correlation. 


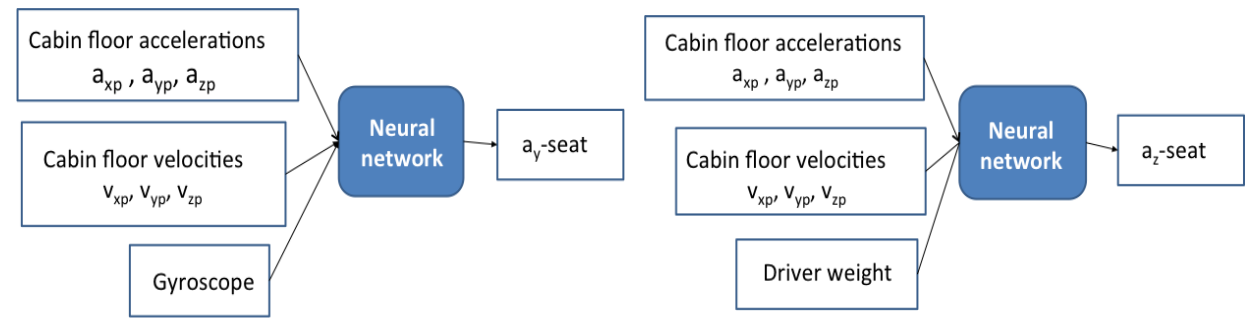

Figure 11: Neural networks for modelling the seat-driver interface accelerations.

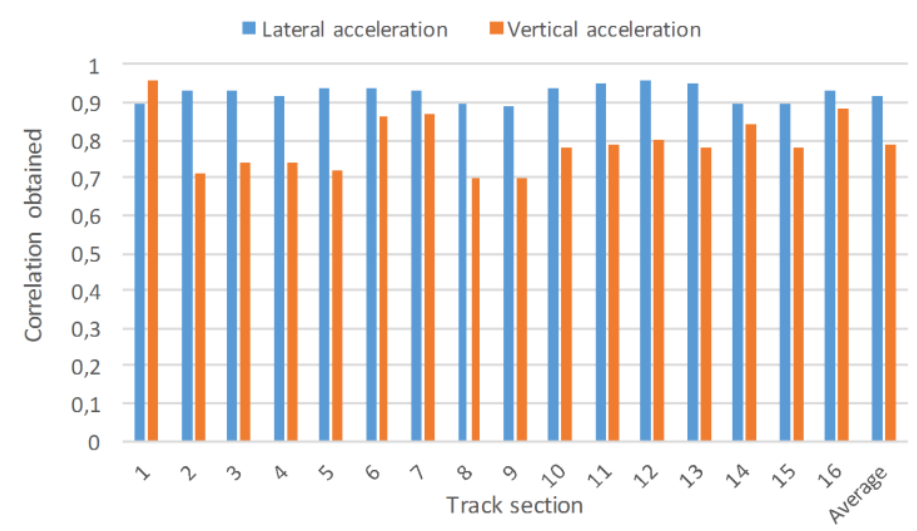

Figure 12: Networks training results.

\section{RESULTS AND DISCUSSION}

For the validation of the complete ANN obtained, segments that had not been used for their training and meeting different track qualities, speeds and layouts, corresponding to the remaining $30 \%$ of the data, were used. The response of the network to various application cases was evaluated. Table IV shows the characteristics of the sections used for the validation.

Table IV: Validation section used.

\begin{tabular}{|c|c|c|c|}
\hline Validation section & Number of samples & Speed $(\mathrm{km} / \mathrm{h})$ & Track quality \\
\hline 1 & 11000 & $116-122$ & QN1 - QN2 \\
\hline 2 & 27800 & $98-108$ & QN2 - QN3 \\
\hline 3 & 106040 & $70-95$ & QN2 - QN3 \\
\hline
\end{tabular}

Table V shows the performance results of the ANN that models the seat-driver interface lateral acceleration. A good correlation is obtained between the ANN output and the real system outputs for the same floor acceleration input, especially in the sections of lower track quality. Being the correlation values acceptable, the $R M S$ and Peak Factors obtained with the ANN output data - which are the values used for the determination of the vibration dose received by the driver - show a low error with respect to those obtained in the real system, less than $7.5 \%$.

Table V: Validation results; complete neural network for modelling the driver-seat interface lateral acceleration.

\begin{tabular}{|c|c|c|c|c|}
\hline $\begin{array}{c}\text { Validation } \\
\text { section }\end{array}$ & Results & $\begin{array}{c}\text { Correlation } \\
\text { coefficient }\end{array}$ & $\begin{array}{c}\boldsymbol{R} \text { RMS } \\
\text { [error \%] }\end{array}$ & $\begin{array}{c}\text { Peak factor } \\
\text { [error \%] }\end{array}$ \\
\hline \multirow{2}{*}{1} & Simulated & \multirow{2}{*}{0,88} & $0,137[7,4 \%]$ & $4,64[3 \%]$ \\
\cline { 2 - 3 } \cline { 4 - 5 } & Actual & \multirow{2}{*}{0,89} & 0,148 & 4,78 \\
\hline \multirow{2}{*}{2} & Simulated & $0,146[6,0 \%]$ & $5,16[0,8 \%]$ \\
\cline { 2 - 3 } & Actual & & 0,155 & 5,2 \\
\hline \multirow{2}{*}{3} & Simulated & \multirow{2}{*}{0,94} & $0,227[6,6 \%]$ & $0,163[1,2 \%]$ \\
\cline { 2 - 3 } \cline { 4 - 5 } & Actual & & 0,242 & 0,165 \\
\hline
\end{tabular}


Fig. 13 shows a comparison between the ANN outputs and the actually measured lateral acceleration on the instrumented seat pad for the same cabin floor vibration input, in both time and frequency domains. A very good fit can be observed, corresponding to the good correlation, $R M S$ and peak values described above. For the ANN modelling the driver-seat interface vertical accelerations, the same validation was carried out, with the same track sections data. Table VI shows the validation results. Even though no reliable information was available about the driver(s) weight(s), a driver weight of $80 \mathrm{~kg}$ was used. Good correlation was found between the neural network output data and the actual vertical acceleration measured on the seat instrumented pad, as well as low errors in the RMS and the Peak Factor values. The bigger error value can be attributed to the absence of information about the driver(s) weight(s). In this case the relative error is bigger due to the low level of vibration. However, for bigger absolute values of vibration error tends to be lower.
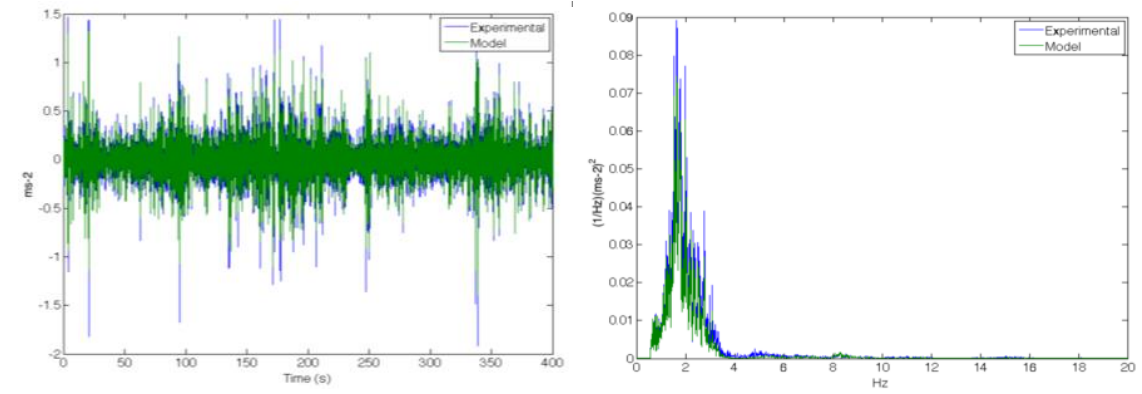

Figure 13: Comparison between actual and simulated signals in time and frequency, lateral acceleration.

Table VI: Validation results; complete neural network for modelling the driver-seat interface vertical acceleration.

\begin{tabular}{|c|c|c|c|c|}
\hline $\begin{array}{c}\text { Validation } \\
\text { section }\end{array}$ & Results & $\begin{array}{c}\text { Correlation } \\
\text { coefficient }\end{array}$ & $\begin{array}{c}\boldsymbol{R M S} \\
{[\text { Error \%] }}\end{array}$ & $\begin{array}{c}\text { Peak factor } \\
{[\text { Error \%] }}\end{array}$ \\
\hline \multirow{2}{*}{1} & Simulated & \multirow{2}{*}{0,83} & $0,050[8 \%]$ & $0,166[4,2 \%]$ \\
\cline { 2 - 3 } \cline { 4 - 5 } & Actual & & 0,054 & 0,173 \\
\hline \multirow{2}{*}{2} & Simulated & \multirow{2}{*}{0,78} & $0,053[9,4 \%]$ & $0,168[9,6 \%]$ \\
\cline { 2 - 3 } \cline { 4 - 5 } & Actual & & 0,058 & 0,135 \\
\hline \multirow{2}{*}{3} & Simulated & \multirow{2}{*}{0,7} & $0,049[3,9 \%]$ & $0,154[7,1 \%]$ \\
\cline { 2 - 3 } & Actual & & 0,051 & 0,165 \\
\hline
\end{tabular}

A comparison in time and frequency domain between the actual and simulated signals was also carried out. As shown in Fig. 14, the vertical acceleration neural network very reasonably reproduces the dynamic behaviour, being this especially true if the wider spectral content of the signal when training the corresponding neural network is taken into account. Note that, despite both neural networks tend to underestimate the vibration levels, the errors seem to be systematic, so a correction ratio can be used for increasing the results accuracy.
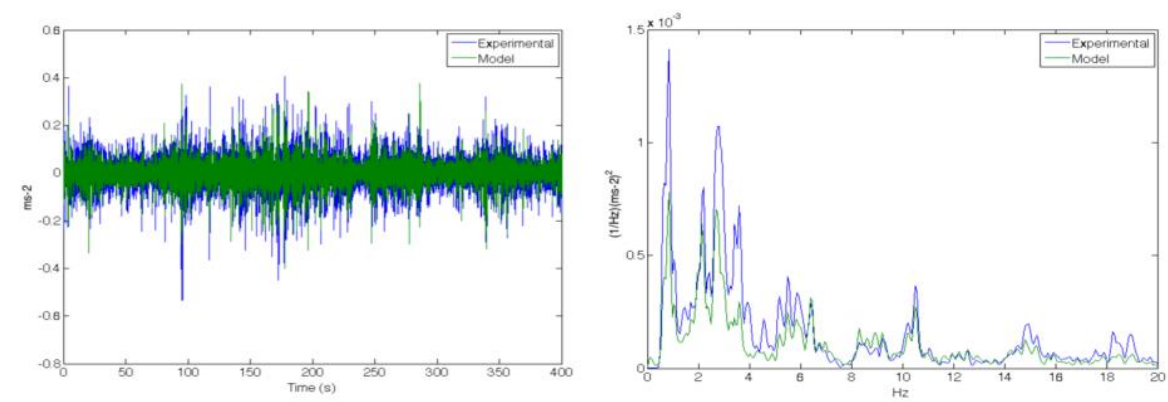

Figure 14: Comparison between actual and simulated signals in time and frequency, vertical acceleration. 


\section{CONCLUSION}

This work presents an Artificial Neural Network formulation and methodology to predict the vibration at the train seat-driver and the driver's vibration dose by using the cabin floor acceleration and train speed and angular velocity data obtained during the train dynamic approval tests. After a proper selection of the network input signals and an adequate signal pre-processing, good correlation is found between the neural network output and the actual seat measurements taken for the network training. Even better correlation is found in the vibration dose indicators. This allows for reducing the manipulability of the vibration dose results, as the information required for the calculation is not limited to that where instrumented pad data is made available. Driver's weight, normally not registered in the dynamic approval tests, does not have a remarkable influence on the lateral acceleration simulation, but a bigger one on the vertical, being the maximum error obtained less than $10 \%$. This Artificial Neural Network approach can be used for the assessment of the effects of vibration in driver's health. Instead of performing costly measurement tests for each journey of a driver shift, a preliminary assessment of the vehicle-seat-track section can be accomplished using this ANN model and track data. Only when the vibration dose is near the limit defined, a whole measurement test should be performed. This method could also be used for the behaviour assessment of different seats for a correct seat selection.

\section{REFERENCES}

[1] Directive 2002/44/EC of the European Parliament and of the Council of 25 June 2002 on the minimum health and safety requirements regarding the exposure of workers to the risks arising from physical agents (vibration)

[2] ISO Standard 2631-1. (1997). Mechanical vibration and shock - Evaluation of human exposure to whole-body vibration - Part 1: General requirements, $2^{\text {nd }}$ edition, International Organization for Standardization

[3] ISO 2631-4:2001. Mechanical vibration and shock - Evaluation of human exposure to wholebody vibration - Part 4: Guidelines for the evaluation of the effects of vibration and rotational motion on passenger and crew comfort in fixed-guideway transport systems

[4] ISO 2631-5:2004. Mechanical vibration and shock - Evaluation of human exposure to wholebody vibration - Part 5: Method for evaluation of vibration containing multiple shocks

[5] Johanning, E.; Fischer, S.; Christ, E.; Göres, B. (2002). Whole-body vibration exposure study in U.S. railroad locomotives - an ergonomic risk assessment, AIHA Journal, Vol. 63, No. 4, 439446, doi:10.1080/15428110208984732

[6] Johanning, E.; Landsbergis, P.; Fischer, S.; Luhrman, R. (2004). Back disorder and ergonomic survey among North American railroad engineers, Transportation Research Record: Journal of the TRB, Vol. 1899, 145-155, doi:10.3141/1899-19

[7] Hoey \& Farina, P.C. Lawsuit, professional illness, from http://www.hoeyfarina.com/railroadhflocomotivevibration, accesed on 15-05-2016

[8] Hannon and Palermo, Lawsuit, professional illness, from http://www.hannonandpalermo.com/verdicts.html, accesed on 16-11-2013

[9] HG.org Legal Resources, Lawsuit, cumulative trauma injury, from https://www.hg.org/article.asp?id=7150, accesed on 15-05-2016

[10] Stein, G. J.; Múčka, P.; Clement, P. (2004). Vibration mitigation by intelligent control of seat suspension damper, Proceedings of Euromech Colloquium 455 on Semi-Active Vibration Supression, 45-47

[11] Stein, G. J.; Múčka, P.; Clement, P. (2004). Identification and optimization of vertical seat suspension system for a railway vehicle, Proceedings of $9^{\text {th }}$ Mini Conference on Vehicle System Dynamics, Identification and Anomalies, 177-186 
[12] Stein, G. J.; Zahoranský, R.; Múčka, P.; Chmurny, R.; Meyer, H. (2004). On dry friction modelling in simple, kinematically excited, vibration isolation systems, Proceedings of International Conference on Noise and Vibration Engineering, 649-663

[13] Stein, G. J.; Múčka, P. (2005). Analysis of the rail test seat performance in operating conditions, VIBSEAT Project Internal Technical Report

[14] Rantaharju, T.; Mansfield, N. J.; Ala-Hiiro, J. M.; Gunston, T. P (2015). Predicting the health risks related to whole-body vibration and shock: a comparison of alternative assessment methods for high-acceleration events in vehicles, Ergonomics, Vol. 58, No. 7, 1071-1087, doi:10.1080/00140139.2014.959071

[15] Rouss, V.; Charon, W.; Cirrincione, G. (2009). Neural model of the dynamic behaviour of a nonlinear mechanical system, Mechanical Systems and Signal Processing, Vol. 23, No. 4, 11451159, doi:10.1016/j.ymssp.2008.09.004

[16] Tang, H.; Tan, K. C.; Yi, Z. (2007). Neural networks: computational models and applications, Springer, Berlin, doi: $10.1007 / 978-3-540-69226-3$

[17] Xie, S. L.; Zhang, Y. H.; Chen, C. H.; Zhang, X. N. (2013). Identification of nonlinear hysteretic systems by artificial neural network, Mechanical Systems and Signal Processing, Vol. 34, No. 12, 76-87, doi:10.1016/j.ymssp.2012.07.015

[18] Saric, T.; Simunovic, G.; Simunovic, K. (2013). Use of neural networks in prediction and simulation of steel surface roughness, International Journal of Simulation Modelling, Vol. 12, No. 4, 225-236, doi:10.2507/IJSIMM12(4)2.241

[19] Alem, N. (2005). Application of the new ISO-2631-5 to health hazard assessment of repeated shocks in U.S. Army vehicles, Industrial Health, Vol. 43, No. 3, 403-412, doi: $10.2486 /$ indhealth.43.403

[20] Ji, X. (2015). Evaluation of suspension seats under multi-axis vibration excitations - A neural net model approach to seat selection, $\mathrm{PhD}$ Thesis, The University of Western Ontario, London, Ontario, Canada

[21] Gohari, M.; Rahman, R. A.; Tahmasebi, M.; Nejat, P. (2014). Off-road vehicle seat suspension optimisation, Part I: derivation of an artificial neural network model to predict seated human spine acceleration in vertical vibration, Journal of Low Frequency Noise, Vibration and Active Control, Vol. 33, No. 4, 429-441, doi:10.1260/0263-0923.33.4.429

[22] Gohari, M.; Rahman, R. A.; Raja, R. I.; Tahmasebi, M. (2012). A novel artificial neural network biodynamic model for prediction seated human body head acceleration in vertical direction, Journal of Low Frequency Noise, Vibration and Active Control, Vol. 31, No. 3, 205-216, doi:10.1260/0263-0923.31.3.205

[23] Gohari, M.; Rahman, R. A.; Tahmasebi, M. (2014). Prediction head acceleration from hand and seat vibration via artificial neural network model, Applied Mechanics and Materials, Vol. 471, 161-166, doi:10.4028/www.scientific.net/AMM.471.161 